\title{
Melatonin binding sites and their role in seasonal reproduction
}

\author{
D. J. Kennaway and S. A. Rowe \\ Department of Obstetrics and Gynaecology, University of Adelaide, Adelaide, \\ South Australia 5005
}

\begin{abstract}
The pineal gland has a major role in the translation of scotophase duration into a hormonal signal by the hormone melatonin. Animals such as sheep, goats and deer use the seasonal variation of this signal to coordinate reproductive behaviour with the environment. Despite intensive research over more than 30 years the site(s) of action of melatonin and the resultant intracellular responses are still not clear. This review discusses recent work that has localized the site of action of melatonin in sheep using administration into the hypothalamus in vivo as well as studies on putative melatonin receptors in the pars tuberalis and brain. There is clear evidence that melatonin acting at the level of the pars tuberalis is involved in the seasonal regulation of prolactin secretion, but the evidence for involvement of the pars tuberalis in seasonal reproduction is not compelling. Localized administration of melatonin to the sheep brain revealed that areas anatomically distinct from the pars tuberalis, the ventromedial and arcuate nuclei, simulated seasonal reproductive changes in rams and ewes. Recent studies on brain melatonin binding sites in our laboratory have shown that an antagonist of tissue transglutaminase, Bacitracin, as well as substrates for the enzyme inhibit binding of melatonin to brain membranes. As a working hypothesis, we propose that pineal melatonin secretion alters seasonal reproduction by interactions with a neural transglutaminase at the synapse of neurones involved in the control of GnRH secretion. Synaptic transglutaminase is implicated in the control of the release of neurotransmitter via the synaptic vesicle associated protein, synapsin 1; activation of transglutaminase results in the covalent modification of synapsin 1 such that vesicles are not released from the cytoskeleton. Seasonal variation in the duration of melatonin secretion may result in similar variations in the duration of suppression and activation of transglutaminase. The resultant changes in transmitter release may then be responsible for the seasonal neuronal plasticity previously observed in GnRH neurones.
\end{abstract}

\section{Introduction}

Since the discovery of melatonin in bovine pineal glands, research has progressed through distinct phases. Originally melatonin was associated with pigmentation in Amphibia, but it plays no such role in mammals. However, the pineal gland and melatonin are recognized as key components in the transfer of external environmental signals to the hypothalamo-pituitary-gonadal axis in many vertebrates. It is not the aim of this review to discuss in depth the vast literature on the effects of the environment upon reproduction in mammals, as this has been covered extensively elsewhere. Instead this review will cover the recent advances in our understanding of the way in which the daily rhythmic melatonin signal is 
interpreted at the tissue and cellular level, with particular emphasis in sheep and, where appropriate, in other laboratory animals.

Until 1975, melatonin was extremely difficult to measure in blood except by elaborate and tedious bioassays. Inferences about the physiological role(s) of melatonin were made on the basis of pineal content of the hormone using chemical assays or more commonly by analysis of the enzymes involved in its synthesis, for example serotonin- $N$-acetyltransferase and hydroxyindole- $O$-methyltransferase. Because the animals had to be killed before the analyses, this era of pineal research was dominated by rodent studies. The development of three different radioimmunoassays for melatonin within 2 years provided pineal researchers for the first time with a simple tool for the study of the pineal gland and its hormone melatonin in blood (Arendt et al., 1976; Rollag and Niswender, 1976; Kennaway et al., 1977). There followed a period of about 5 years when the seasonal patterns of melatonin secretion were described in controlled conditions in domestic ruminants (Rollag and Niswender, 1976; Kennaway et al., 1983). The key features of melatonin secretion identified were that (i) melatonin secretion is low during the day and increases markedly at night, (ii) the maximum night-time melatonin concentrations do not vary markedly during the year and (iii) the duration of high night-time melatonin secretion varies with the seasons, and is longest during the shortest days.

The 1980 s saw interest switch to investigations of the effect of removal of melatonin following pinealectomy and the administration of the hormone on reproductive processes. Research on the hamster, a seasonal breeder, established the paradigms for such investigations in domestic ruminants. For example, it was found that in hamsters, which normally undergo gonadal regression during winter, melatonin administration during a simulated summer photoperiod mimicked the natural seasonal regression (Tamarkin et al., 1976). It was found that the time of day the melatonin was administered was critical for the induction of gonadal regression; injections in the morning were ineffective, whereas injections a few hours before normal darkness mimicked the effects of exposure to short daylength. As a result of studies on small laboratory species like hamsters, melatonin was considered as an anti-gonadotrophic hormone, and this concept shaped the thinking about melatonin for many years (Reiter, 1980). For those working in agricultural research, it was already well established that domesticated ruminants, such as sheep. goats and deer, were stimulated into reproductive activity by short daylength. For example, the onset of breeding activity is advanced in sheep by similar changes in lighting duration to those used to induce gonadal regression in hamsters. When melatonin was administered in late afternoon to sheep maintained in long daylength, the onset of ovarian cyclicity was advanced as predicted (Kennaway et al., 1982b) and testicular function was stimulated (Lincoln and Kelly, 1989), Subsequently, Bittman and Karsch (1984) provided definitive evidence that the duration of the nightly melatonin signal is responsible for the seasonal alterations in the sensitivity of the hypothalamo-pituitary axis to steroidal feedback (Karsch et al., 1988). The major questions being addressed in the 1990 s relate to the mechanisms underlying the ability of melatonin to alter the hypothalamo-pituitary-gonadal axis. There is reason to challenge the notion that melatonin behaves like other hormones that endocrinologists have become familiar with, based upon the critical role the timing of melatonin secretion and administration have in the physiological actions of the hormone. Although the duration of the melatonin signal seems to be of central importance for melatonin action and thus may well fit into a simple endocrine paradigm, there are anomalies that are difficult to reconcile with duration of melatonin driving seasonality. For example, $13 \mathrm{~h}$ of darkness (and thus approximately $13 \mathrm{~h}$ of melatonin secretion) stimulates or inhibits reproductive function depending on whether the previous photoperiod was longer or shorter than $13 \mathrm{~h}$ (Hoffman et al., 1986; Robinson and Karsch, 1987). The intracellular actions of melatonin must first be defined before this and other questions regarding the role of the pineal gland in reproduction can be answered.

\section{Site of Action of Melatonin}

It is interesting and surprising that, in the 36 years since the discovery of melatonin, there have been significant advances in our understanding of endocrinology, and yet there is still no clear indication of where or how melatonin acts to alter reproductive function. Clearly, melatonin may act at either the 
brain or the gonads. There have been many reports of alterations of steroid synthesis by melatonin, often only at pharmacological doses, but in some cases within the physiological range (Baratta and Tamanini, 1992). Although there are reports of specific binding sites for $\left[^{125}\right]-2$-iodomelatonin in gonadal tissue of some avian species (Ayre et al., 1992), there are no reports of such binding in mammals. Sites of action within the brain have been supported by many studies. For example, Cardinali et al. (1973) injected $\left[{ }^{3} \mathrm{H}\right]$ melatonin into rats and observed a higher concentration of melatonin in the hypothalamus, compared with the rest of the brain. Withyachumnarnkul et al. (1986) obtained similar results, and it is now generally recognized that the brain, and the hypothalamus in particular, is the likely site of action of melatonin. In addressing the question of the site of action of melatonin, it is also important to consider how the secreted hormone might reach its putative target sites. Shaw et al. (I989) showed that in sheep, the concentration of melatonin in the lateral ventricles is ten times that in the cisterna magna or jugular blood. Although it has not been reported, concentrations of melatonin in the third ventricle can be expected to be of equal or greater magnitude and as a consequence, circumventricular organs (for example the suprachiasmatic nucleus (SCN) and pars tuberalis) would be exposed to these high concentrations. Elegant studies by Lynch and co-workers using timed intra-hypothalamic injections (Glass and Lynch, 1982) and intermittent exposure to melatonin via implants (Dowell and Lynch, 1987) have further established that parts of the anterior hypothalamus are mediators of the reproductive effects of melatonin in the white footed mouse (Peromyscus leucopus).

The site of action of melatonin in the ruminant brain has not been extensively studied. Two groups have recently addressed the question using approaches similar to those used by Lynch and co-workers by using micro-implants of melatonin in rams (Lincoln and Maeda, 1992a) and ewes (Malpaux et al., 1993). The implants were constructed from stainless steel cannulae (inside diameter 0.415 and $0.45 \mathrm{~mm}$, respectively) with melatonin fused inside the tip. Evaluation of the release rates in vitro indicated that the implants delivered 3.4 $\pm 0.4 \mu \mathrm{g}$ day ${ }^{-1}$ and $5.5 \pm 0.4 \mu \mathrm{g}$ day ${ }^{-1}$, respectively (Lincoln and Maeda, 1992a; Malpaux ef al, 1993). Lincoln and Maeda (1992a) placed the implants into the preoptic area and medial basal hypothalamus of sexually inactive Soay rams maintained in long days ( $16 \mathrm{~h}$ light: $8 \mathrm{~h}$ dark). Implants located in the region of the medial basal hypothalamus increased FSH secretion within 7-14 days of the start of treatment and accelerated testicular recrudescence in all 12 animals, compared with only two positive responses in the 12 animals bearing implants in the preoptic area (Fig. I). Decreased basal prolactin secretion was evident within 1 week (Lincoln and Maeda, 1992b). Subsequently Lincoln (1992) reported similar endocrine effects of intermittent administration of melatonin into the medial basal hypothalamus using microdialysis probes delivering $0.5 \mu \mathrm{g} \mathrm{h}^{-1}$ during the $8 \mathrm{~h}$ preceding darkness in rams held in a photoperiod of $16 \mathrm{~h}$ light: $8 \mathrm{~h}$ dark.

Malpaux et al. (1993) used ovariectomized, oestradiol-implanted ewes maintained in a photoperiod of $16 \mathrm{~h}$ light: $8 \mathrm{~h}$ dark for ten weeks to investigate the effects of the melatonin implants. Under these conditions, basal LH secretion is normally low, and it was hypothesized that melatonin treatment would increase $\mathrm{LH}$ concentrations in the blood. Implants placed in the preoptic area, or anterior hypothalamus, had no effect upon plasma LH, whereas seven of 12 animals with implants in the medial basal hypothalamus responded with increased $\mathrm{LH}$ secretion after about 40 days (Fig. I). The timing and pattern of the $\mathrm{LH}$ changes were similar to those observed after exposure to short daylength or treatment with s.c. melatonin implants (Regulin).

In summary, these experiments confirmed that continuous treatment with melatonin in sheep maintained in long days is interpreted by the animals as if they were exposed to short days (Kennaway et al, I982a). It was proposed that neural structures in the vicinity of the medial basal hypothalamus were the likely target sites for the reproductive and prolactin suppressive effects of melatonin in these two studies,

\section{Melatonin Binding Studies}

If melatonin is like other hormones, it is to be expected that it will alter the function of its target tissue(s) after binding to specific receptors. Despite the availability of high specific activity $\left[{ }^{3} \mathrm{H}\right]$ melatonin (about $80 \mathrm{Ci} \mathrm{mmol}^{-1}$ ) for many years, little progress was made in the identification of melatonin receptors until 


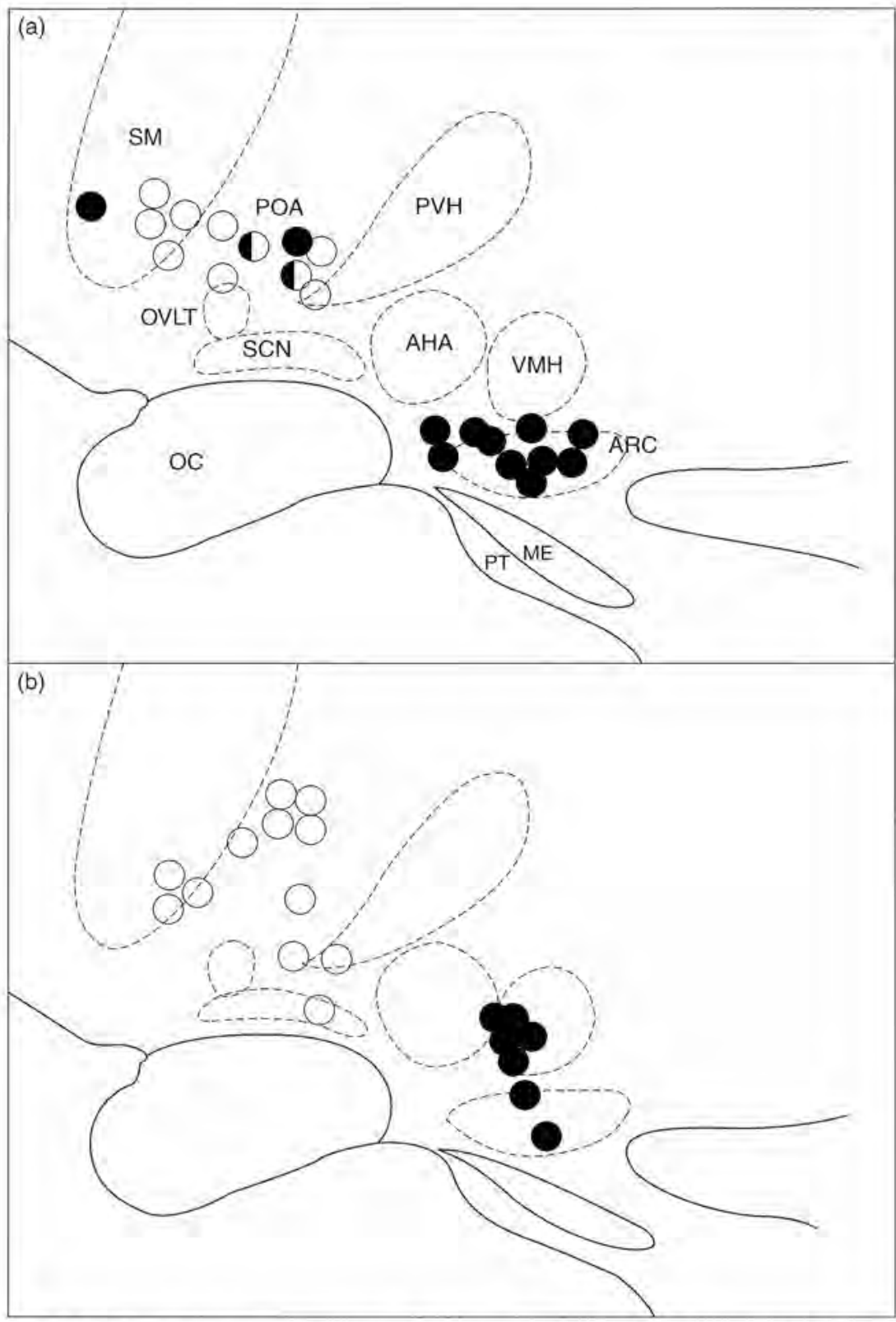

Fig. 1. (a) Approximate positions of melatonin microimplants in the medial basal hypothalamus and preoptic area of adult Soay rams redrawn from Lincoln and Maeda (1992a) The reproductive response induced by the implants are indicated ( full response, i.e. maximum diameter of testes reached significantly earlier than in controls, $\mathbf{O}$ : intermediate response, and $\mathrm{O}$ : no response). (b) Approximate positions of melatonin microimplants in the preoptic area and anterior, dorsolateral and medial basal hypothalamus of adult ewes. Redrawn from Malpaux ef al. (1993). (-) Animals in which LH secretion was stimulated; (O) animals not responding. (Note: not all negative data are included.) ARC: arcuate nucleus; AHA: anterior hypothalamic area; OC: optic chiasma; OVLT; organum vasculosum laminae terminalis; ME: median eminence; POA: preoptic area; PT: pars tuberalis; PVH: paraventricular nucleus; SCN: suprachiasmatic nucleus; $S M$ : medial septal area; $\mathrm{VMH}$ : ventromedial hypothalamic nucleus. 
an rodinated analogue ([ ${ }^{125} \mathrm{I}-2$-iodomelatonin) became available. This radioligand has been used to establish that melatonin binds with high affinity $\left(<100 \mathrm{pmol}^{-1}\right)$ to membrane preparations of discrete brain nuclei (Vanecek, 1988). Vanecek et al. (1987) were also the first to use the new high specific activity melatonin analogue $\left[{ }^{125} \mathrm{I}\right]$-2-iodomelatonin for in vitro autoradiography in rat brain. Two areas of intense labelling, the median eminence and the SCN were identified; later studies have attributed the median eminence labelling to a thin layer of pars tuberalis cells (Williams and Mórgan, 1988). Autoradiography in vitro has proved to be a useful tool for identifying discrete regions of high-density putative receptors in the brain, and several groups have used this approach to identify melatonin binding sites in ruminants. Morgan et al. $(1989 \mathrm{c})$ identified intense labelling by $\left[{ }^{125} \mathrm{I}\right]$-2-iodomelatonin in the pars tuberalis of sheep and this has been confirmed in sheep (Bittman and Weaver, 1990; Pelletier et al., 1990; de-Reviers et al, 1991; Stankov et al., 1991; Helliwell and Williams, 1992) and goats (Deveson et al., 1992). Bittman and Weaver (1990) described additional brain melatonin binding sites in the septohypothalamic nuclei and hippocampus with less binding to the medial preoptic nucleus and very little binding in the SCN. de-Reviers et al. (1991) investigated binding in the region of the pars tuberalis, pituitary and SCN, and reported intense labelling only in the pars tuberalis. These early results contrast with those of Stankov et al. (1991) and Deveson et al. (1992), who both reported [ ${ }^{125} \mathrm{I}$ ]-2-iodomelatonin binding sites in the SCN and confirmed specific binding in the preoptic nucleus and cortex of sheep and goats, whereas Deveson et al. (1992) found binding sites in the goat hippocampus.

These results raise important questions about the likely site of action of melatonin in the brain that is responsible for mediating the reproductive effects of the hormone demonstrated in the experiments of Lincoln and Maeda (1992a) and Malpaux et al. (1993). As discussed above, microimplants placed in the medial preoptic area, the site of perikarya for neurones containing GnRH (Lehman et al, 1986), do not accelerate reproductive activity in sheep, despite the presence of melatonin binding sites in that region. On the contrary, melatonin implants in the medial basal hypothalamus, an area apparently devoid of melatonin binding sites, are effective in simulating short daylength changes in reproductive function. $\mathrm{A}$ possible explanation for these findings is that the melatonin diffused from the tip of the cannula to a site of high receptor density such as the pars tuberalis. Both Lincoln and Maeda (1992a) and Malpaux ef al. (1993) addressed this possibility by determining the diffusion of melatonin using $\left.~^{\mathrm{I25}} \mathrm{I}\right]$-2-iodomelatonin incorporated into some of the implants. The area of diffusion was determined to be $0.75 \mathrm{~mm}$ and $0.55 \mathrm{~mm}$, respectively, and no radioactivity was detected in the pituitary stalk or pars tuberalis (Malpaux et al. 1993). While not excluding the pars tuberalis as the site of action of melatonin in sheep, the question of how the melatonin reached the pars tuberalis remains, since it must have diffused much further than the experiments with the $\left[^{125} \mathrm{I}\right]-2$-iodomelatonin had indicated. Alternatively, melatonin may have diffused to the binding sites previously identified elsewhere in the hypothalamus, for example the ventromedial nucleus (Bittman and Weaver, 1990), or entered the ventricular fluid.

The melatonin binding sites in the oyine pars tuberalis are the best characterized of any tissue. The ovine pars tuberalis has the advantage that it can be harvested relatively easily from abattoir material to provide viable cell and membrane preparations. The high specific activity melatonin analogue $\mathrm{I}^{125} \mathrm{I} \mathrm{l}$-2-iodomelatonin binds to membrane preparations with high affinity ( $32 \mathrm{pmol} \mathrm{I}^{-1}$ ) and a high degree of specificity, consistent with the normal circulating concentrations of melatonin in blood and cerebrospinal fluid and known physiological activities of melatonin precursors, metabolites and analogues (Morgan et al, 1989c). Considerable effort has gone into the study of the consequences of occupation of the melatonin receptor, i.e. the potential second messenger systems and specific effects upon protein synthesis. Melatonin was shown to inhibit forskolin-induced adenyl cyclase activity in intact pars tuberalis cells with an $\mathrm{IC}_{50}$ value of $6 \mathrm{pmol}^{-1}$ (Morgan et al., 1989a), although later studies indicated that $406 \mathrm{pmol} \mathrm{I}^{-1}$ was required to achieve the same inhibition (Morgan et al., 1991b). Melatonin has no effect upon forskolin-induced adenyl cyclase activity in homogenates of the same cell preparations (Morgan et al., 1989a). As yet the endogenous activator of cyclic AMP in the pars tuberalis has not been found, although it has been argued that there must be such an input, because melatonin fails to inhibit basal cyclic AMP concentrations (Morgan et al., 1994). Guanine nucleotides (GTP $\gamma \mathrm{S}$ and GTP) decrease the affinity of the binding sites for $\left[{ }^{125} 1\right]-2$-iodomelatonin leading to the hypothesis that the melatonin binding site on the pars tuberalis cell membrane is linked to regulatory $\mathrm{G}$ proteins (Morgan et al., 1989b). In an important șeries of studies, Morgan et al. (1993) studied the impact of melatonin 
upon protein synthesis in the pars tuberalis. Forskolin stimulated the labelling of at least eight proteins and melatonin $\left(10 \mu \mathrm{mol} \mathrm{I}^{-1}\right)$ counteracted the stimulatory effect of all but one protein (prolactin) (Morgan et al., 1993). The studies failed to identify a protein specific to the pars tuberalis and the proteins stimulated by forskolin in the pars tuberalis were also present in pars distalis cells. Nevertheless, melatonin inhibited the synthesis and secretion of these proteins only in the pars tuberalis. Morgan et al. (1993) concluded that the pars tuberalis product may not be peptidergic, but a compound synthesized by enzyme action and then secreted. Alternatively, pars tuberalis cells may synthesize a protein lacking methionine which was used as the marker in these studies.

\section{Seasonal Breeding and the Role of Melatonin Target Tissues}

In attempting to understand the possible role of melatonin in the pars tuberalis, it is worthwhile to review briefly what is known about it. Wittkowski et al. (1992) stated that the pars tuberalis "... in mammals consists of strands of a bilayered to multi-layered glandular epithelium surrounding the hypophysial stalk and extending along the ventral surface of the median eminence. The secretory cells of the pars tuberalis are in close contact with the capillaries of the primary plexus of the portal vessel system, as are the nerve endings of the median eminence. Because of these spatial relations, secretory products of the pars tuberalis as well as neuropeptides of the hypothalamic nerve endings are released into the portal system and are spread throughout the pars distalis by the secondary capillary plexus." In studies on the ultrastructure of cells of the ovine pars tuberalis, Morgan et al. (I991a) found two types of secretory cell differing in the abundance of dense core granules. The most abundant cells $(90 \%)$ were either agranular or sparsely granulated compared with the remaining cells with abundant dense core vesicles. The agranular secretory cells were the melatonin responsive cells in the ovine pars tuberalis.

The inhibition of forskolin-stimulated adenyl cyclase activity and modulation of $\left[{ }^{125} \mathrm{I}-2\right.$ iodomelatonin binding suggests that occupation of the melatonin receptor alters cellular activity, probably by altering protein synthesis. The question arising from the research on interactions of melatonin with the pars tuberalis is how could the pars tuberalis mediate the reproductive and hormonal effects attributed to changes in melatonin secretion during the year? Morgan et al. (1994) suggested that the pars tuberalis produced a small molecular weight substance through an enzymatically controlled pathway. This molecule would enter the brain from the circulation and influence neural centres involved in the timing of gonadotrophin release. According to this hypothesis, "... at the pars tuberalis, melatonin acts as an inhibitory input, counteracting a presumed stimulatory input, yet to be identified, where it blocks the secretion of a putative pars tuberalis-specific secretion. This creates an inversion of the melatonin signal. The pars tuberalis-specific secretion then influences a (putative) circannual timer located in the brain." Alternatively, effects of melatonin on the pars tuberalis may be only modulatory for seasonality, influencing the output of the GnRH neurones in the medial basal hypothalamus and the output of cells in the pars distalis (Fig. 2).

There is very little experimental evidence to support the notion that the pars tuberalis secretions affect a circannual timer in the brain, but there is evidence that interactions between melatonin and the pars tuberalis affect pituitary function directly. Lincoln and Clarke (1994) used hypothalamo-pituitary disconnected rams to determine whether an intact hypothalamo-pituitary axis is obligatory for both the seasonality and decreased basal secretion of prolactin induced by melatonin implants (Kennaway et al., 1982a). Pituitary disconnected rams continued to exhibit photoperiod driven changes in prolactin secretion temporally identical to that observed in control animals, although the blood concentrations were generally higher. Treatment of the animals with constant-release implants of melatonin when the prolactin concentrations were high during long days resulted in the expected decrease in prolactin secretion in both the hypothalamo-pituitary disconnected and control rams. Because the pituitary was surgically and physically isolated (by aluminium foil) from the brain, it was concluded that the changes induced in prolactin secretion by photoperiod and melatonin occurred through an effect of melatonin at the pars tuberalis or pars distalis. In the absence of any evidence of melatonin binding sites in the sheep pars distalis, the pars tuberalis is the probable source of the effects of melatonin on prolactin secretion through an unknown humoral factor(s). 


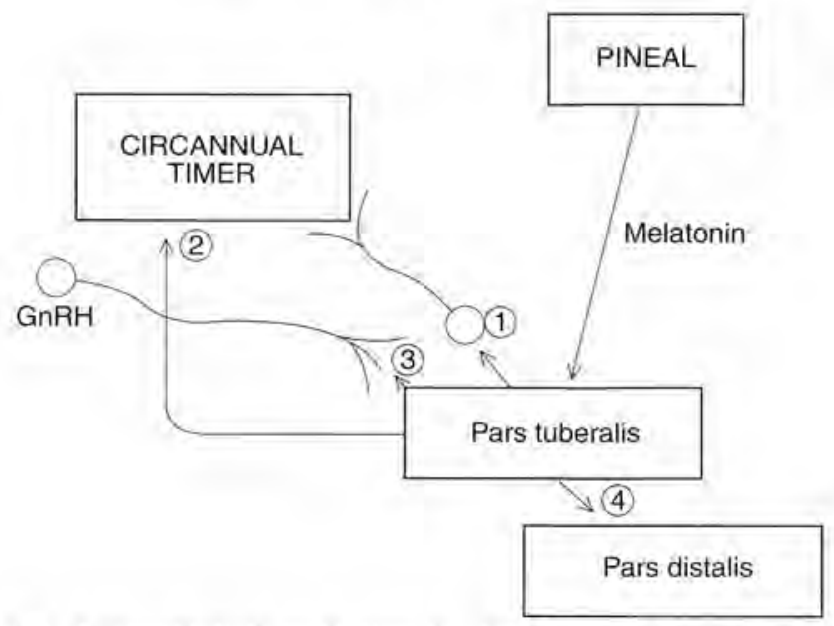

Fig. 2. Hypothetical mechanism for the circannual reproductive effects of melatonin involving the pars tuberalis. Melatonin inhibits the secretion of a putative substance that is specific to the pars tuberalis. This secretory product then influences a putative circannual timer in the brain by directly influencing mediobasal hypothalamic neurones projecting to the circannual timer (1) or via blood or cerebrospinal fluid (2). In addition, melatonin may influence GnRH neurones in the medial basal hypothalamus (3) and also the output of the pars distalis (4). Redrawn from Morgan et al. (1994).

\section{Neurones as Melatonin Targets}

As discussed previously, there is evidence, mainly from binding studies, that melatonin may act at the neuronal level. One reported site of melatonin concentration is the SCN. The SCN is a critical component in the system linking changes in environmental light with the neuroendocrine axis and is characterized by a self-sustained circadian rhythm of neural activity (Inouye and Kawamura, 1979). In the context of the pineal gland and melatonin, the SCN is required for the generation of the melatonin rhythm and its modulation by light; destruction of the SCN totally abolishes the melatonin rhythm in sheep (Locatelli et al., 1994). A part from the fact that the SCN accumulates $\left[{ }^{125} \mathrm{I}\right]$-2-iodomelatonin in vitro (Vanecek et al., 1987), it is also clearly a physiologically relevant site of melatonin action, as administration of melatonin has been shown to alter metabolic activity (Cassone of al, 1987) and neuronal firing of SCN neurones (Shibata et al., 1989) and to entrain behavioural rhythms (Redman et al., 1983) and its own rhythm (Humlova and Illnerova, 1990). The extremely small size and shape of the SCN of most animals, including sheep, has precluded conventional receptor analyses on tissue homogenates or cellular components. Instead, quantitative radiography has been used to characterize high-affinity binding sites in vitro $\left(K_{\mathrm{d}}\right.$ value $\left.40 \mathrm{pmol}^{-1}\right)$ that are regulated by calcium and are specific for melatonin (Laitinen et al., I989). There are also reports of rhythmic changes in the melatonin binding site density in the SCN, and less binding is evident during the night than during the day (Laitinen $e t$ al., 1989). There are, as yet, no reports indicating that occupation of the melatonin receptor in the SCN activates or inhibits synthesis of specific proteins or alters cellular activity in any way, although there is a rhythm of protein synthesis in the rat SCN (Shibata et al., 1992). No comparable experiments have been performed in sheep.

Melatonin binding sites in sheep and goats are located in other parts of the hypothalamus (Bittman and Weaver, 1990; Stankov et al., 1991; Deveson et al., 1992), probably associated with neurones (although possible binding to astrocytes cannot be ruled out). It has been proposed that seasonal breeding and the concomitant changes in sensitivity to steroidal feedback arise from modification of neural connections within the hypothalamus (Lehman et al., 1986). Could melatonin binding sites in the $\mathrm{SCN}$ and elsewhere be involved in this type of neural plasticity? 

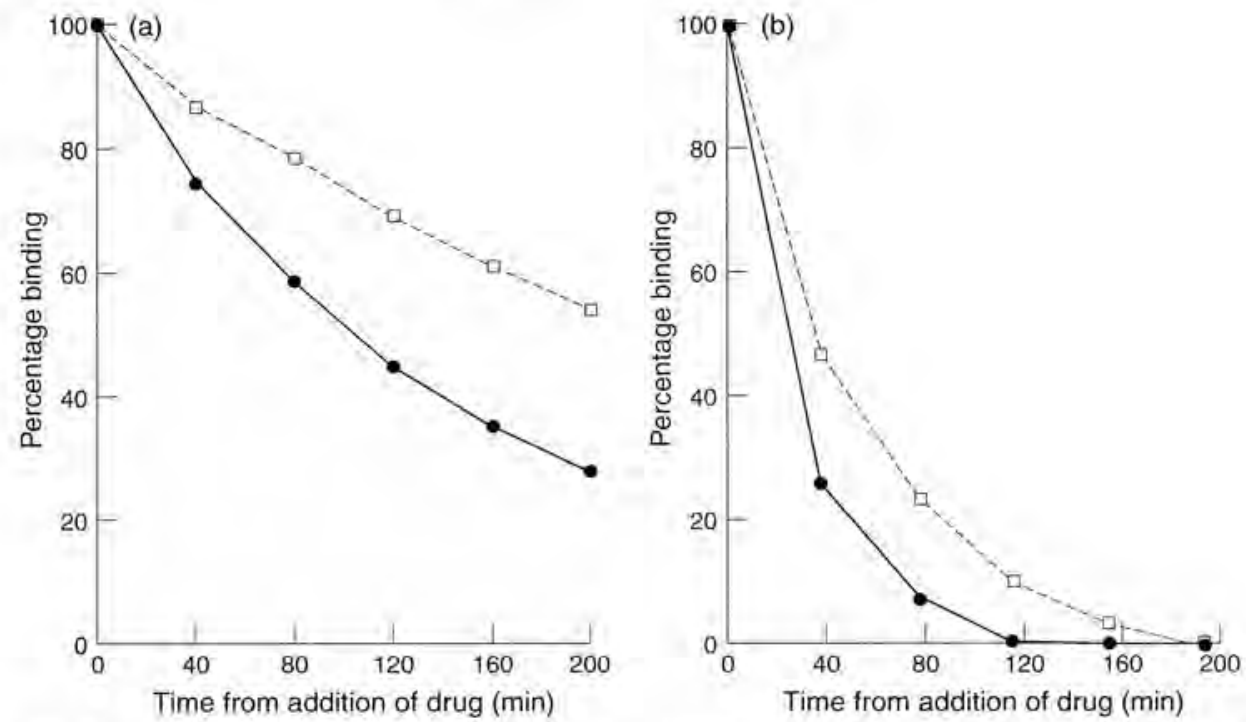

Fig. 3. Effect of $7 \mathrm{mmol}$ Bacitracin $1^{-1}(\bullet)$ and $1 \mu \mathrm{mol}$ melatonin $1^{-1} \Leftrightarrow$ on dissociation of $\left[{ }^{125} \mathrm{I} \mid-2\right.$-iodomelatonin and $\left[{ }^{3} \mathrm{H}\right]$ melatonin binding to chicken brain membranes. Membranes (10 $\mathrm{mg}$ wet mass tissue) were incubated with (a) 10 pmol $\left[^{125} \mathrm{I}\right]-2$-iodomelatonin $\mathrm{I}^{-1}$ or (b) $95 \mathrm{pmol}\left[^{3} \mathrm{H}\right]$ melatonin $1^{-1}$ for $2 \mathrm{~h}$ at $25^{\circ} \mathrm{C}$. Binding was determined at various times after the addition of the drugs. Note that when ${ }^{125} \mathrm{I}-2$-iodomelatonin is used as the radioligand, dissociation is slow and incomplete compared with $\left[{ }^{3} \mathrm{H}\right]$ melatonin as reported by Kennaway et al (in press), Bacitracin accelerated dissociation of both radioligands from the binding sites.

Neural binding sites are difficult to study in most animals because they are either specifically located in small discrete nuclei or in low abundance. The chicken brain is an exceptional source of melatonin binding sites and the binding sites are clearly located in brain areas important for processing visual information (Siuciak et al. 1991). Sugden and Chong (1991) compared the binding sites in the chicken brain with those in the ovine pars tuberalis and concluded that the chicken brain sites are pharmacologically similar to those of the ovine pars tuberalis. We also characterized melatonin binding sites in chicken brain using both $\left[{ }^{125} \mathrm{I}\right]$-2-iodomelatonin and $\left[{ }^{3} \mathrm{H}\right]$ melatonin (Kennaway et al., in press) and, although we observed some anomalies in the behaviour of the two ligands, it is clear that the tissue provides an excellent model system for studies of melatonin action in neural tissue. In studies on the instability of melatonin binding protein at temperatures greater than $25^{\circ} \mathrm{C}$, we observed that the antibiotic Bacitracin caused a paradoxical rapid dissociation of both iodinated and tritiated melatonin radioligands from the binding sites (Kennaway, D. J. and Rowe, S. A., unpublished). Bacitracin is not only an antibiotic and protease inhibitor, but also a potent competitive inhibitor of transglutaminase (Davies et al., 1980). Transglutaminases catalyse the post-translational modification of proteins by transamidation of available glutamine residues, resulting primarily in the formation of glutamyl-lysine cross-links, as well as the incorporation of polyamines into suitable protein substrates. Figure 3 shows the effect of adding Bacitracin $\left(7 \mathrm{mmol} \mathrm{1}^{-1}\right)$ or melatonin $\left(1 \mu \mathrm{mol} \mathrm{1}^{-1}\right)$ to chicken brain membranes preincubated with 10 pmol $\left[{ }^{125} \mathrm{I}\right]-2$-iodomelatonin $\mathrm{I}^{-1}$ and 90 pmol $\left[^{3} \mathrm{H} /\right.$ melatonin $\mathrm{I}^{-1}$ for $2 \mathrm{~h}$ at $25^{\circ} \mathrm{C}$. Treatment with both compounds resulted in rapid dissociation of the ligand from the binding sites, with a rate similar to that observed after exposure to GTP but slower than that observed with excess melatonin (Kennaway ef al., in press). Figure 4 shows the effect of incubation of membranes with various doses of Bacitracin and two substrates of transglutaminase (dansyl cadaverine and putrescine) from $10 \mathrm{mmol} \mathrm{I}{ }^{-1}$ to $10 \mathrm{mmol} \mathrm{I}^{-1}$. It is clear that both the substrates and the inhibitor of transglutaminase decrease melatonin binding to chicken brain membranes. Cellular transglutaminases are present in nervous tissue (Hand et al., 1993). We also identified transglutaminase-like activity and melatonin binding sites in crude membrane preparations and synaptosomes of chicken brain and both the enzyme activity and melatonin binding are inhibited by 


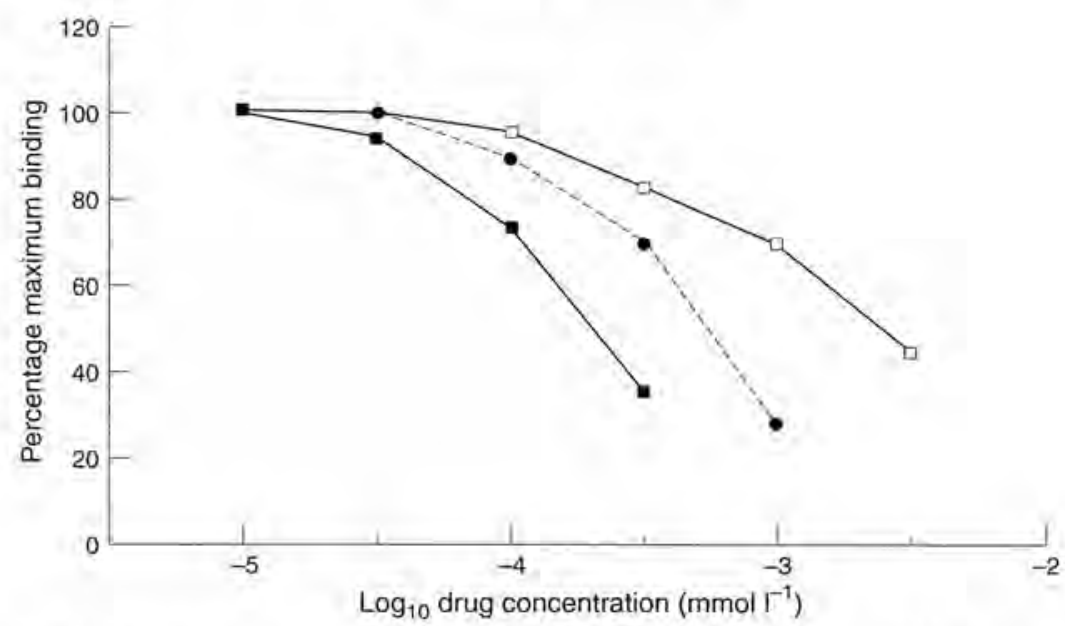

Fig. 4. Effect of dansyl cadaverine $(\bullet)$, Bacitracin $(\bullet)$ and putrescine $(\Leftrightarrow)$ on $\left[{ }^{3} \mathrm{H}\right]$ melatonin binding to chicken brain membranes. Membranes (IO mg wet mass) were incubated with 95 pmol $\left[{ }^{3} \mathrm{H}\right.$ ]melatonin $\mathrm{I}^{-1}$ at $25^{\circ} \mathrm{C}$ for $2 \mathrm{~h}$ in the presence of increasing concentrations of the test compound. The data are presented as a percentage of the maximum of specifically bound hormone. The results are from a single experiment which was performed twice.

Bacitracin, dansyl cadaverine and GTP across the same concentration ranges (D.J. Kennaway and S.A. Rowe, unpublished). Both Bacitracin and dansyl cadaverine reduce the affinity and apparent number of binding sites (Fig. 5). At the time of preparation of this review, we have been unable to demonstrate inhibitory or stimulatory effects of melatonin on transglutaminase activity in chicken brain preparations using the common artificial substrates dimethyl casein and $\left[{ }^{3} \mathrm{H}\right]$ putrescine. Studies are in progress with natural transglutaminase substrates to determine the nature of the interaction between the enzyme and melatonin binding sites.

\section{Melatonin-Transglutaminase Interactions and the Control of Seasonality: a Hypothesis}

As a working hypothesis, we propose that the melatonin binding protein is associated with a transglutaminase-like enzyme and it is through interactions with this enzyme that melatonin alters reproductive and other functions. It is interesting to note in this context that the evidence used to implicate $\mathrm{G}$ proteins in melatonin binding, i.e. GTP-induced dissociation of ligand binding, can be used to support interactions between transglutaminase and melatonin. Transglutaminase possesses a GTP-binding site which is different from the catalytic site and possesses GTPase activity (Lee et al, 1993). Similarly, while there is considerable evidence that melatonin binding to brain tissue is calcium dependent (Laitinen et al., 1990), brain transglutaminase activity also depends on calcium (Gilad and Varon, 1985). Nakaoka et al. (1994) showed that a GTP-binding protein $\mathrm{G}_{\mathrm{h}}$ associated with $\alpha_{1}$ adrenergic receptors is a tissue transglutaminase. They concluded that the $G \alpha_{h}$ subunit " . , is a multifunctional GTP-binding protein that can mediate both receptor-stimulated phospholipase $\mathrm{C}$ activation and transglutamination", Micromolar concentrations of GTP $\gamma$ S inhibit the transglutaminase activity of G $\alpha_{h}$ and this effect is augmented by receptor activation, which suggests that GTP may be a negative regulator of transglutaminase activity. Because receptor activation stimulates the binding of GTP to $\mathrm{G} \alpha_{\mathrm{h}}$, it may act as a switch to allow $\mathrm{G} \alpha_{h}$, to function as a signalling molecule rather than as a transglutaminase. Hydrolysis of GTP would terminate the signal transduction and restore the transglutaminase function of $\mathrm{Ga}$ (Nakaoka et al., 1994). 


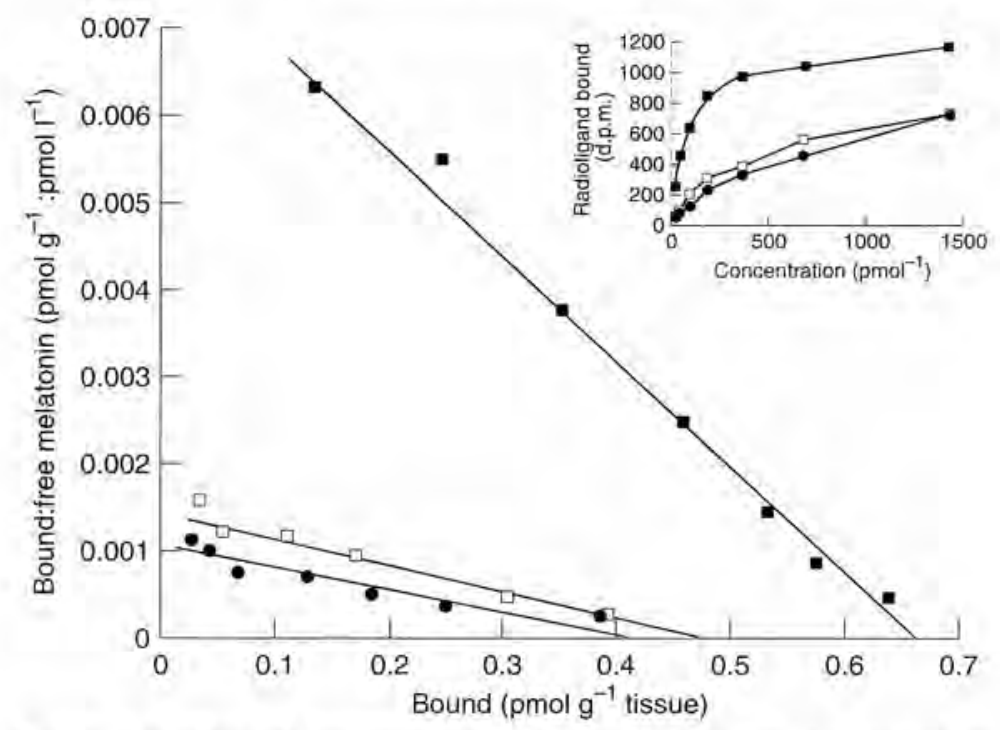

Fig. 5. The effect of Bacitracin and dansyl cadaverine on the binding of $\left[{ }^{3} \mathrm{H}\right]$ melatonin to chicken brain membranes. Membranes (10 mg wet mass tissue) were incubated with $\left[{ }^{3} \mathrm{H}\right]$ melatonin $\left(25-1450 \mathrm{pmol} \mathrm{I}^{-1}\right)$ at $25^{\circ} \mathrm{C}$ for $2 \mathrm{~h}$ in the presence of buffer (*), Bacitracin $\left(7 \mathrm{mmoll}^{-1} \Rightarrow\right.$ or dansyl cadayerine (I mmol $\mathrm{I}^{-1}, \bullet$ ). The inset shows the specific binding to the membranes (d.p.m. bound per $10 \mathrm{mg}$ tissue) versus the radioligand concentration. Nonspecific binding was defined using $1 \mu \mathrm{mol}$ melatonin $1^{-1}$. The main chart shows the transformation of the data according to Scatchard. The apparent $K_{\mathrm{d}}$ value was $82 \mathrm{pmol}^{-1}$ in the absence of drug and this was reduced to $327 \mathrm{pmol}^{-1}$ in the presence of both Bacitracin and dansyl cadaverine. The apparent number of binding sites was also reduced by $30 \%$ and $40 \%$, respectively. The experiment has been performed three times with similar results.

Brain transglutaminase has been implicated in the release of neurotransmitter (Pastuszko et al., 1986) and Facchiano et al. (1993) provided the molecular framework for how this might be achieved. Synaptic vesicles containing transmitter are tethered to the cytoskeleton by interactions with the vesicle associated protein synapsin 1 . Upon stimulation, neurotransmitter is released from vesicles docked at the terminal and new synaptic vesicles uncouple from the cytoskeleton in preparation for another transmitter discharge. Activation of transglutaminase results in the covalent modification of synaptic vesicle-bound synapsin 1 and this may then reduce the amount of transmitter released. If there is an interaction between transglutaminase, melatonin and synapsin, the changes in the duration of melatonin during the night through the seasons may modulate neuronal activity in specific neurones. The changes in transmitter release may then be responsible for the neuronal plasticity observed in the GnRH neurones responsible for seasonal breeding (Karsch et al,, 1987).

There is another possible consequence of interactions between melatonin and transglutaminase, Transglutaminase-induced protein cross-linking may be essential for receptor-mediated endocytosis of some protein and polypeptide hormones (Davies et al., 1980). Grasso and Reichert (1992) showed that transglutaminase activation stabilized FSH binding to its testicular receptor and suggested that the enzyme may regulate the way in which gonadal cells respond to hormone binding. In this case, occupation of melatonin binding sites and the associated modulation of transglutaminase could alter post-receptor binding cascades without any changes in the number of protein hormone receptors that are occupied. 


\section{Conclusion}

We know so much about the synthesis and secretion of melatonin and about its role in seasonal reproduction, but we still know very little about where and how melatonin acts. However, the studies reviewed in this paper indicate clearly that these questions may be answered soon. A site of action for melatonin in the pars tuberalis and certain neural centres in the brain are suggested by both experiments in vivo and binding studies. The intracellular consequences of occupation of melatonin-binding sites are not well understood and indeed may vary between the glandular pars tuberalis cells and neuronal tissue. It will be important to study both systems to determine how melatonin, the hormone of darkness', can alter reproductive activity. Finally in view of the slow progress in identifying specific classical hormone-receptor actions of melatonin, it is worth continuing to explore possible alternative mechanisms that are conducive with what is known of the physiological actions of melatonin. As discussed in this review, one function of melatonin may involve modulation of neural transmission through interactions with synaptic vesicles in specific hypothalamic nuclei.

Original research performed in this laboratory was supported by a grant from the NHMRC of Australia

\section{References}

Arendt I. Paunier L and Sizonenko PC (1976́) Melatonin radioimmunoassay Journal of Clinical Endocrinology and Metabolism $40347-350$

Ayre EA, Yuan H and Pang SF (1992) The identification of ${ }^{125}$ I-labelled iodomelatonin-binding sites in the testes and ovaries of the chicken (Gallus domesticus) Joumal of Endocrinology 133 5-11

Baratta M and Tamanini C (1992) Effect of melatonin on the in vitro secretion of progesterone and estradiol 17 beta by ovine granulosa cells Acta Endocrinologica 127 $360-370$

Bittman EL and Karsch FJ (1984) Nightly duration of pineal melatonin secretion determines the reproductive response to inhibitory day length in the ewe Biology of Reproduction 30 585-593

Bittman EL and Weaver DR (1990) The distribution of melatonin binding sites in neuroendocrine tissues of the ewe Biology of Reproduction 43 986-993

Cardinali DP, Hyyppa MT and Wurtman RJ (1973) Fate of intracisternally injected melatonin in the rat brain Neuroendocrinology $12 \quad 30-40$

Cassone VM, Roberts MH and Moore RY (1987) Melatonin inhibits metabolic activity in the rat suprachiasmatic nuclei Neuroscience Lefters $81 \quad 29-34$

Davies PJA, Davies DR, Levitzki A, Maxfield FR, Milhaud P. Willingham MC and Pastan IH (1980) Transglutaminase is essential in receptor-mediated endocytosis of alpha-2macroglobulin and polypeptide hormones Nature 283 162-167

de-Reviers MM, Tillet $Y$ and Pelletier J (1991) Melatonin binding sites in the brain of sheep exposed to light or pinealectomized Neturoscience Lefters 121 17-20

Deveson S, Howarth J, Arendt J and Forsyth I (1992) In vitro autoradiographical localization of melatonin binding sites in the caprine brain foumal of Pineal Restarch 13-6-12

Dowell SF and Lynch GR (1987) Duration of the melatonin pulse in the hypothalamus controls testicular function in pinealectomized mice (Peromyscus leucopus) Biology of Reproduction 36 1095-1101
Facchiano F, Benfenati F, Valtorta F and Luini A (1993) Covalent modification of synapsin 1 by a tetanus toxin-activated transglutaminase Joumal of Biological Chemistry 268 4588-4591

Gilad GM and Varon LE (1985) Transglutaminase activity in rat brain: characterization, distribution, and changes with age Joumul of Neurochemistry $451522-1520$

Glass JD and Lynch GR (1982) Diurnal rhythm of response to chronic intrahypothalamic melatonin injections in the white-footed mouse, Peromyscus lencopus Neuroendocrinology 35 117-122

Grasso P and Reichert LE (1992) Stabilization of folliclestimulating hormone-receptor complexes may involve calciumidependent transglutaminase activation Molecular and Cellular Endocrinology 87 49-56

Hand D, Perry MJM and Haynes LW (1993) Cellular transglutaminases in neural development Intemational Joumal of Developmental Neuroscience 11 709-720

Helliwell RJA and Williams LM (1992) Melatonin binding sites in the ovine brain and pituitary: characterization during the oestrous cycle Journal of Neuroendocrinology 4 287-294

Hoffman K, Illnerova H and Vanecek J (1986) Change in duration of the night time melatonin peak may be a signal driving photoperiodic responses in the Djungarian hamster (Phodopus sungorus) Neuroscience Letters 67 68-72

Humlova $\mathrm{M}$ and Illnerova $\mathbf{H}$ (1990) Melatonin entrains the circadian rhythm in the rat pineal $\mathrm{N}$-acetyltransterase activity Neuroendocrinology 52 196-199

Inouye ST and Kawamura H (1979) Persistence of circadian rhythmicity in a mammalian hypothalamic "island" containing the suprachiasmatic nucleus Proceedings of the National Acadeny of Sciences USA 76 5962-5966

Karsch F], Lehman MN and Silyerman AJ (1987) Seasonal plasticity in synaptic input to luteinising hormone-releasing hormone (LHRH) neurons in the sheep Society for Neuroscience Abstracts 13 I527 (Abstract)

Karsch F), Malpaux B, Wayne NL and Robinson JE (1988) Characteristics of the melatonin signal that provide the photoperiodic code for timing seasonal reproduction in the ewe Reproduction Nutrition and Deoelopment 28 459-472 
Kennaway DJ, Frith RG, Phillipou G, Matthews CD and Seamark RF (1977) A specific radioimmunoassay for melatonin in biological tissue and fluids and its validation by gas chromatography-mass spectrometry Endocrinology 101 $119-127$

Kennaway DJ, Gilmore TA and Seamark RF (1982a) Effects of melatonin implants on the circadian rhythm of plasma melatonin and prolactin in sheep Endocrinology $\mathbf{1 1 0}$ 2186-2188

Kennaway DJ, Gilmore TA and Seamark RF (1982b) Effect of melatonin feeding on serum prolactin and gonadotropin levels and the onset of seasonal estrous cyclicity in sheep Endocrinology $1101760-1772$

Kennaway DJ, Sanford LM, Godfrey B and Friesen HG (1983) Patterns of progesterone, melatonin and prolactin secretion in ewes maintained in four different photoperiods Journal of Endocrinology $97229-242$

Kennaway DJ, HugeI HM and Rowe SA Characterisation of the chicken brain melatonin binding protein using iodinated and tritiated ligands Joumal of Pincal Resanch (in press)

Laitinen IT, Castren E Vakkuri O and Saavedra IM (1989) Diurnal rhythm of melatonin binding in the rat suprachiasmatic nucleus Endocrinology 124 1585-1587

Laitinen JT, Flugge G and Saavedra JM (1990) Characterization of melatonin receptors in the rat area postrema: modulation of affinity with cations and guanine nucleotides Neurocidocrinology 51 619-624

Lee KN. Arnold SA, Birckbichler PJ, Patterson MK, Fraji BM, Taheuchi $Y$ and Carter HA (1993) Site-directed mutagenesis of human tissue transglutaminase: $\mathrm{Cys}-277$ is essential for transglutaminase activity but not for GTPase activity Biochimica of Biophysica Acta 1202 1-6

Lehman MN, Robinson JE, Karsch FJ and Silverman AJ (1986) Immunocytochemical localization of luteinizing hormonereleasing hormone (LHRH) pathways in the sheep brain during anestrus and the mid-luteal phase of the estrous cycle Joumal of Comparative Neurology 244 19-35

Lincoln GA (1992) Administration of melatonin into the mediobasal hypothalamus as a continuous or intermittent signal affects the secretion of follicle stimulating hormone and prolactin in the ram Joumal of Pineal Research 12 $135-144$

Lincoln GA and Clarke IA (1994) Photoperiodically-induced cycles in the secretion of prolactin in hypothalamopituitary disconnected rams: evidence for translation of the melatonin signal in the pituitary gland Joumal of Neuroendocrinology 6 25I-260

Lincoln GA and Kelly RW (1989) Test of ML2.3 as an antagonist to the effects of melatonin in the ram Jourmal of Reproduction and Fertility $86737-743$

Lincoln GA and Maeda KI (1992a) Reproductive effects of placing micro-implants of melatonin in the mediobasal hypothalamus and preoptic area in rams fostrial of Endocrinology 132 201-215

Lincoln GA and Maeda KI (1992b) Effects of placing microimplants of melatonin in the mediobasal hypothalamus and preoptic area on the secretion of prolactin and beta-endorphin in rams Journal of Endocrinology 134 $437-448$

Locatelli A, Caldani M, Tessonneaud A, Cooper HM and ViguierMartinez MC (1994) A new surgical approach to the ram suprachiasmatic nucleus Journal of Neuroscience Methods $\mathbf{5 1}$ 189-195
Malpaux B, Daveau A, Maurice F, Gayrard V and Thiery JC (1993) Short-day effects of melatonin on luteinizing hormone secretion in the ewe: evidence for central sites of action in the mediobasal hypothalamus Biology of Reproduction 48 752-760

Morgan PJ, Lawson W. Davidson G and Howell HE (1989a) Melatonin inhibits cyclic AMP production in cultured ovine pars tuberalis cells Joumal of Molecular Endocrinology 3 R.5-R8

Morgan PJ, Lawson W, Davidson G and Howell HE (1989b) Guanine nucleotides regulate the affinity of melatonin receptors on the ovine pars tuberalis Neuroendocrinology $\mathbf{5 0}$ $359-362$

Morgan PI, Williams LM, Davidson G, Lawson W and Howell HE (1989c) Melatonin receptors on ovine pars tuberalis: characterization and autoradiographical localization Jounal of Neuroendocrinology 1 1-4

Morgan PJ, King TP, Lawson W. Slater D and Davidson G (1991a) Ultrastructure of melatonin-responsive cells in the ovine pars tuberalis Cell and Tissue Research 263 529-534

Morgan PJ, Lawson W and Davidson G (1991b) Interaction of forskolin and melatonin on cyclic AMP generation in pars tuberalis cells of ovine pituitary Joumal of Neuroendocrinology 3 497-501

Morgan PJ, Barrett P. Davidson G and Lawson W (1993) Melatonin regulates the synthesis and secretion of several proteins by pars tuberalis cells of the ovine pituitary Journal of Nearoendocrinalogy 4 557-563

Morgan P], Barrett P, Howell HE and Helliwell R (1994) Melatonin receptors: localization, molecular pharmacology and physiological significance Neurochemistry Intemational 24 101-146

Nakaoka H, Perez DM, Baek KJ, Das T, Husain A, Misono K, Im $M$ and Graham RM (1994) $G_{h}$; a GTP-binding protein with transglutaminase activity and receptor signalling function Science 264 1593-1596

Pastuszko A, Wilson DF and Erecinska M (1986) A role for transglutaminase in neurotransmitter release by rat synaptosomes Jouryal of Neurochemistry 46 499-508

Pelletier J, Castro B, Roblot G, Wylde R and de-Reviers MM (1990) Characterization of melatonin receptors in the ram pars tuberalis: influence of light Acta Endocrinologica 123 $557-562$

Redman J, Armstrong S and Ng KT (1983) Free-running activity rhythins in the rat: entrainment by melatonin Science $\mathbf{2 1 9}$ 1089-1091

Reiter RJ (1980) The pineal and its hormones in the control of reproduction in mammals Endocrine Reviews 1 109-131

Robinson JE and Karsch FJ (1987) Photoperiodic history and a changing melatonin pattern can determine the neuroendocrine response of the ewe to daylength Joumal of Reproduction and Fertility 80 159-165

Rollag MD and Niswender GD (1976) Radioimmunoassay of serum concentrations of melatonin in sheep exposed to different lighting regimes Endocrinology 98 482-489

Shaw PF, Kennaway DJ and Seamark RF (1989) Evidence of high concentrations of melatonin in lateral ventricular cerebrospinal fluid of sheep loumal of Pineal Research 6 201-208

Shibata S. Cassone VM and Moore RY (1989) Effects of melatonin on neuronal activity in the rat suprachiasmatic nucleus in vitro Neuroscience Letters 97 140-144 
Shibata S, Hamada I, Tominaga K and Watanabe S (1992) An in vitro circadian rhythm of protein synthesis in the rat suprachiasmatic nucleus under tissue culture conditions Brain Reseitrch $\mathbf{5 8 4} 25 \mathrm{I}-256$

Siuciak JA, Krause DN and Dubocovich ML (1991) Quantitative pharmacological analysis of $2-^{125} \mathrm{I}$-iodomelatonin binding sites in discrete areas of the chicken brain Joumal of Neuroscience 11 2855-2804

Stankov B, Cozzi B, Lucini V, Fumagalli P, Scaglione F and Fraschini F (1991) Characterization and mapping of melatonin receptors in the brain of three mammalian species: rabbit, horse and sheep. A comparative in vitro binding study Neurcendocrinelogy 53 214-221

Sugden D and Chong NW (1991) Pharmacological identity of $2-\left[^{125}\right.$ Iliodomelatonin binding sites in chicken brain and sheep pars tuberalis Brain Research 539 151-154

Tamarkin L, Westrom WK, Hamill AI and Goldman BD (1976) Effect of melatonin on the reproductive systems of male and female Syrian hamsters: a diumal rhythm in sensitivity to metatonin Endocrinology 99 1534-1541

Vanecek J (1988) Melatonin binding sites Joumial of Neurochemistry 51 1436-1440

Vanecek J, Pavlik A and Illnerova H (1987) Hypothalamic melatonin receptor sites revealed by autoradiography Brain Research 435.359-362

Williams LM and Morgan P] (1988) Demonstration of melatonin-binding sites on the pars tuberalis of the rat Journal of Endocrinology 119 RI-R3

Withyachumnarnkul B, Limpanawattanakul $\mathrm{M}$ and Trakulrungsi W (1980) Retention of radioactive substances in the hypothalamus, anterior pituitary, and reproductive organs of male rats after ${ }^{3} \mathrm{H}$-melatonin administration Life Science 38 $1757-1765$

Wittkowski WH, Schulze-Bonhage AH and Bockers TM (1992) The pars tuberalis of the hypophysis: a modulator of the pars distalis? Acta Endocrinologica $126285-290$ 